\title{
Preoperative Quantitative MR Tractography Compared with Visual Tract Evaluation in Patients with Neuropathologically Confirmed Gliomas Grades II and III: A Prospective Cohort Study
}

\author{
Anna F. Delgado, ${ }^{1,2}$ Markus Nilsson, ${ }^{3}$ Francesco Latini, ${ }^{4}$ \\ Johanna Mårtensson, ${ }^{1}$ Maria Zetterling, ${ }^{4}$ Shala G. Berntsson, ${ }^{5}$ \\ Irina Alafuzoff, ${ }^{6}$ Jimmy Lätt, ${ }^{7}$ and Elna-Marie Larsson ${ }^{1}$ \\ ${ }^{1}$ Department of Surgical Sciences, Radiology, Uppsala University, 75105 Uppsala, Sweden \\ ${ }^{2}$ Department of Neuroradiology, Karolinska University Hospital, Department of Clinical Neuroscience, \\ Karolinska Institute, 17177 Stockholm, Sweden \\ ${ }^{3}$ Bioimaging Center, Lund University, 22100 Lund, Sweden \\ ${ }^{4}$ Department of Neuroscience, Neurosurgery, Uppsala University, 75105 Uppsala, Sweden \\ ${ }^{5}$ Department of Neuroscience, Neurology, Uppsala University, 75105 Uppsala, Sweden \\ ${ }^{6}$ Section of Pathology, Uppsala University Hospital and Department of Immunology, Genetics and Pathology, \\ Uppsala University, 75105 Uppsala, Sweden \\ ${ }^{7}$ MR Department, Centre for Medical Imaging and Physiology, Lund University Hospital, 22185 Lund, Sweden \\ Correspondence should be addressed to Anna F. Delgado; anna.falk-delgado@karolinska.se
}

Received 14 December 2015; Accepted 23 March 2016

Academic Editor: Paul Sijens

Copyright ( $) 2016$ Anna F. Delgado et al. This is an open access article distributed under the Creative Commons Attribution License, which permits unrestricted use, distribution, and reproduction in any medium, provided the original work is properly cited.

\begin{abstract}
Background and Purpose. Low-grade gliomas show infiltrative growth in white matter tracts. Diffusion tensor tractography can noninvasively assess white matter tracts. The aim was to preoperatively assess tumor growth in white matter tracts using quantitative MR tractography (3T). The hypothesis was that suspected infiltrated tracts would have altered diffusional properties in infiltrated tract segments compared to noninfiltrated tracts. Materials and Methods. Forty-eight patients with suspected low-grade glioma were included after written informed consent and underwent preoperative diffusion tensor imaging in this prospective review-board approved study. Major white matter tracts in both hemispheres were tracked, segmented, and visually assessed for tumor involvement in thirty-four patients with gliomas grade II or III (astrocytomas or oligodendrogliomas) on postoperative neuropathological evaluation. Relative fractional anisotropy (rFA) and mean diffusivity (rMD) in tract segments were calculated and compared with visual evaluation and neuropathological diagnosis. Results. Tract segment infiltration on visual evaluation was associated with a lower rFA and high rMD in a majority of evaluated tract segments ( $89 \%$ and $78 \%$, resp.). Grade II and grade III gliomas had similar infiltrating behavior. Conclusion. Quantitative MR tractography corresponds to visual evaluation of suspected tract infiltration. It may be useful for an objective preoperative evaluation of tract segment involvement.
\end{abstract}

\section{Introduction}

Gliomas comprise approximately $30 \%$ of all CNS tumors and $80 \%$ of all malignant brain tumors [1]. In adults, these tumors consist mainly of astrocytomas grades II-IV and oligodendrogliomas grades II-III [2]. In suspected low-grade gliomas, preoperative MRI shows a high signal intensity lesion on T2-FLAIR images, usually without but sometimes with faint/patchy contrast enhancement $[3,4]$. Low-grade gliomas are less common than grade IV gliomas, and patients 
with low-grade gliomas are often younger and have a high quality of life and a longer survival [5]. Survival in patients with glioma increases with the extent of tumor resection at surgery $[6,7]$. Total resection of the tumor is hampered by infiltrative growth along white matter tracts [8]. Planning the surgical resection of these tumors is facilitated by knowledge about infiltration of the adjacent tracts. Intraoperative subcortical mapping using direct electrical stimulations under awake surgery is the gold standard to directly assess the functional connectivity of tracts adjacent to the tumor [9]. Retrospective studies have shown increased extent of resection and preserved functions with the help of preoperative physiological MRI, intraoperative neuronavigation, and neurophysiological intraoperative testing [10-12]. Presurgical planning is thus of importance in this group because maximal tumor resection has to be balanced with the preservation of neurological function [13, 14].

Astrocytomas and oligodendrogliomas grade II and grade III have overlapping radiologic features, and on contrast enhanced CT or MRI they can be identified by their lack of typical grade IV features like ring-like contrast enhancement and central necrosis $[15,16]$. Gliomas grade II and grade III can be separated on the basis of cytological features, cell density, and mitotic figures on neuropathological assessment. Grade IV gliomas have neuropathological characteristics of irregular vascularization with areas of necrosis [2]. Despite their relatively sharp demarcation on T2-weighted images, low-grade gliomas are known for their infiltrative growth pattern along white matter tracts $[17,18]$.

Morphological MRI with conventional T1- and T2weighted images and contrast agent injection provides information about tumor location, the extent of bulk tumor growth, and blood-brain-barrier breakdown and edema, but it does not readily aid in the evaluation of specific white matter tracts. White matter tracts can be displaced, infiltrated, or destructed by tumor growth as evaluated by brain tumor specimen for histopathological evaluation [19-21]. Preoperative noninvasive assessment of white matter structure and glioma growth by diffusion MRI is a promising tool in the presurgical clinical evaluation.

DTI (diffusion tensor imaging) enables the depiction of anisotropic diffusion, which is dependent on white matter fiber orientation [22]. Diffusion tensor tractography (DTT) shows anisotropic diffusion, measured with DTI as colorcoded streamlines [23]. DTT depicts white matter fiber orientation and allows visualization of tumor influence on white matter tracts, beyond that of morphological MRI [24]. MD (mean diffusivity) and FA (fractional anisotropy) can be extracted from DTI. MD describes the mean diffusion in tissues and FA describes the directional diffusion in tissues [25]. MD is low in tissue with high cell density and FA is high in tissues with ordered and orientationally coherent microstructure [25]. Previous studies have shown a correlation between lower FA and white matter destruction by tumor. A study by Wang et al. from 2012 demonstrated reduced FA in white matter invaded by tumor cells in a rat glioma model [19]. Reduced FA has also been correlated with increased cell density in gliomas in humans [26].
Earlier studies have evaluated $\mathrm{MD}$ and FA in single regions of interest in gliomas showing differences in diffusion between glioma grades [27, 28]. Retrospective studies have evaluated glioma infiltration in tracts by DTT showing the infiltrative growth pattern in gliomas [29]. Quantitative DTT has been reported to correlate with symptoms in glioma patients [30]. The value of DTT in pre- and perioperative imaging has been studied [11, 12, 31-33]. Although a promising method, DTT has several limitations and clinical implications still need further validation [34].

A well-conducted previous study has evaluated and validated DTT in a cohort of normal individuals [35]. Based on these earlier DTT descriptions, the aim of this study was to compare quantitative analysis of $\mathrm{MD}$ and $\mathrm{FA}$ in tract segments of the major associative, projection, and commissural bundles with visual tract evaluation in patients with nonnecrotic suspected low-grade gliomas and subsequent confirmed neuropathological diagnosis of glioma grade II or grade III. Taking into account the variation in diffusion along the same tract, we systematically divided each bundle into segments using anatomical landmarks [36-38]. To reduce interindividual differences based on, for example, age and degenerative changes in the white matter between patients we normalized the ipsilateral tract segments to the contralateral tract. The resulting DTT findings were compared with visual tract evaluation and neuropathological tumor diagnosis. The hypothesis was that suspected infiltrated tracts would have altered diffusional properties in infiltrated tract segments compared to noninfiltrated tracts.

\section{Materials and Methods}

Fifty consecutive patients were asked to participate in this prospective study, approved by the regional ethical review board in Uppsala (2010/015), which was undertaken from May 2010 to February 2014. Two patients declined participation in the study and were not included. All patients $(n=$ 48) gave written informed consent before taking part in the study. Patients eligible for inclusion were those referred to the neurosurgical department with clinical and radiological suspicion of a low-grade glioma. Inclusion criteria were tumors appearing low-grade on morphological MRI with no contrast enhancement or only patchy and faint contrast enhancement [4]. Exclusion criteria were the appearance of high-grade glioma features on morphological MRI with ringlike contrast enhancement and central necrosis. Previously published results from parts of this cohort have evaluated methionine-PET, perfusion, and diffusion characteristics [39, 40]. No study evaluating diffusion tensor tractography in this cohort has been reported. Included patients underwent presurgical radiological imaging, including morphological and physiological MRI with DTI, except for one patient (patient number 3) who had a biopsy 6 months prior to the study MRI. Patients eligible for tractographic evaluation and statistical analysis were those with a neuropathological report following surgery or biopsy of an astrocytoma or oligodendroglioma grade II or III. Exclusion criteria for statistical analysis were the following: no neuropathological diagnosis 
or diagnosis other than astrocytoma or oligodendroglioma grade II or III on neuropathological assessment.

MRI. MRI was performed on a 3 T scanner (Philips Achieva, Philips Medical Systems, Best, Netherlands) and a 32-channel head coil.

2.1. Morphological MRI. Morphological sequences included axial T2-FLAIR (TR/TE 11,000/125 ms; 90-degree flip angle; $512 \times 512$ matrix; and $0.45 \times 0.45 \times 6.00 \mathrm{~mm}^{3}$ voxel size), axial T1-weighted spin echo sequences (TR/TE $600 / 10 \mathrm{~ms}$; 70degree flip angle; $512 \times 512$ matrix; and $0.45 \times 0.45 \times 5.00 \mathrm{~mm}^{3}$ voxel size) before and after intravenous administration of gadobutrol (Gadovist ${ }^{\circledR}$, Bayer Schering Pharma, Wedding, Berlin, Germany), sagittal T1-weighted 3D turbo field echo (TFE) after contrast agent injection (TR/TE: $8.1 / 3.7 \mathrm{~ms}$; voxel size $1 \times 1 \times 1 \mathrm{~mm}$ ), and sagittal T2-weighted turbo spin echo $(\mathrm{SE})(\mathrm{TR} / \mathrm{TE}=3,000 / 80 \mathrm{~ms}$; slice thickness $=4 \mathrm{~mm}$; and slice gap $=0.8 \mathrm{~mm}$ ). Sequences acquired but not assessed in this study were axial T2-weighted turbo spin echo (SE), coronal T2-FLAIR, and perfusion weighted imaging during contrast agent injection.

2.2. Diffusion MRI. Diffusion MRI was performed with SE EPI sequence with the following scan parameters: TR/TE $6,683 \mathrm{~ms} / 77 \mathrm{~ms} ; 60$ slices with a thickness of $2 \mathrm{~mm}$; SENSE = 2; $128 \times 128$ matrix; FOV $256 \times 256 \mathrm{~mm}$; and diffusion encoding in 48 directions, with $b=1,000 \mathrm{~s} / \mathrm{mm}^{2}$, for a total scan time of 6 minutes. All postprocessing was performed using in-house developed software, implemented in MATLAB (The Mathworks, Natick, MA, USA). Motion and eddy current distortions were corrected by registering the diffusion-weighted volumes to the volume acquired with $b=$ $0 \mathrm{~s} / \mathrm{mm}^{2}$, using ElastiX $[41,42]$. In this process, the diffusionweighted images were smoothed using 3D Gaussian kernel with a full width at half maximum of $2 \mathrm{~mm}$. We used inhouse developed software based on linear least-squares fitting with heteroscedasticity correction. Streamline tractography was performed using the Diffusion Toolkit and TrackVis (Ruopeng Wang, Van J. Wedeen, TrackVis.org, Martinos Center for Biomedical Imaging, Massachusetts General Hospital, MA, USA). The whole brain was seeded from two randomly positioned seeds in each voxel using FA threshold of 0.1 and an angular threshold of 45 degrees.

2.3. Tract Segmentation and Evaluation. ROIs (regions of interest) for tracking were delineated in EvalGUI, in-house developed software, based on earlier white matter atlas descriptions [43-45] and previous tractography evaluation of the normal brain [35]. Tracts were subdivided into segments that were defined based on anatomical landmarks, and ROI-delineation is visualized in Supplementary Figures 1 a-i (see Supplementary Material available online at http://dx.doi.org/10.1155/2016/7671854). These ROIs defined the anatomical landmarks. The ROI positions perpendicular to the tracts defined the segments. ROIs for each tract segment were positioned in the ipsilateral hemisphere and in the contralateral hemisphere in all patients; ROIs were adjusted when tract segment trajectory was altered due to tumor growth. TrackVis was used for visual confirmation of the tract positions (Figures 1(a)-1(i)).

Whole tracts were visually assessed in EvalGUI after selecting ROI positions. Tract segments were visually inspected in 3D using TrackVis. Figure 2 shows an example of the cingulum with associated ROIs and tract segments.

The following tracts were evaluated in all patients: the corticospinal tract, the inferior frontooccipital fasciculus, the retrosplenial and parahippocampal parts of the cingulum [46], the arcuate fasciculus, the inferior longitudinal fasciculus, the uncinate fasciculus, fornix, and the forceps minor of the corpus callosum (Figures 1(a)-1(i)). Segments were numbered 12 or 1-3 from caudal to cranial ones, from anterior to posterior ones, or from midline to lateral ones depending on tract course (Figures 1(a)-1(i)). All tract segments were assessed for infiltration or dislocation by the tumor with reference standard for tumor area set as high signal intensity on T2weighted images by a resident in neuroradiology with 5 years of experience in brain tumor evaluation. A tract segment was visually classified as infiltrated if it coursed through the tumor area defined as high signal intensity on T2-FLAIR weighted images. A tract segment was visually classified as dislocated if it deviated from its expected pathway on FA-color maps and was located outside the increased signal intensity on T2-FLAIR defined as tumor. Tumor location in the left or right hemisphere and lobes was determined on T2-weighted images.

2.4. Neuropathological Evaluation. All histopathological slides were reevaluated by one neuropathologist with extensive clinical experience of glioma diagnosis. The diagnoses followed the 2007 WHO classification of central nervous system tumors. The tumors were classified as either astrocytomas or oligodendrogliomas based on the dominating cell type [2].

2.5. Statistical Analysis. To standardize diffusion measurements, adjust for differences between hemispheres, and decrease interindividual variations between patients, a relative FA (rFA) was calculated for each tract segment by dividing the mean FA in the ipsilateral tract segment by the mean FA in the corresponding contralateral tract segment in each patient. The corresponding calculation was performed for mean MD, yielding relative MD (rMD). The FA and MD in tract segments are the mean values of all voxels in that segment. rFA and rMD were compared between groups based on radiographic features (tumor infiltration, tumor dislocation, and hemisphere location left/right) and neuropathological features (tumor type, tumor grade) with the Mann-Whitney $U$ test. The Wilcoxon matched pairs test was used to evaluate differences in rFA between different segments of a tract partially infiltrated by tumor. The chisquared test was used to investigate the distributions of visually infiltrating gliomas between grades II and III. The cut-off for significant results was set to a $p$ value of $<0.05$. Statistical analyses were performed in Statistica version 12 (StatSoft, Dell Software, TX, USA). 


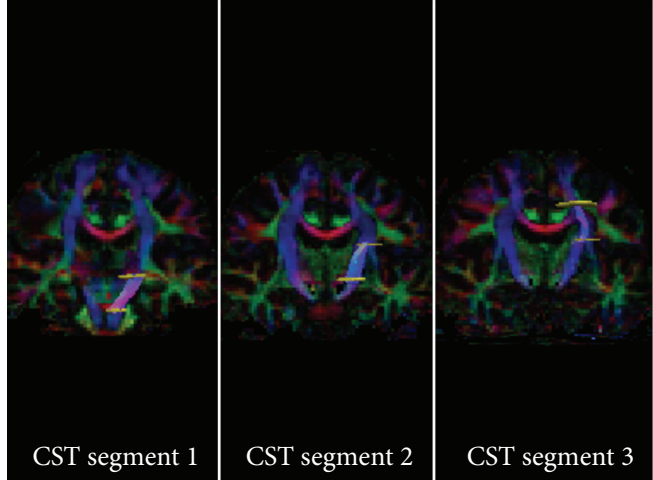

(a)

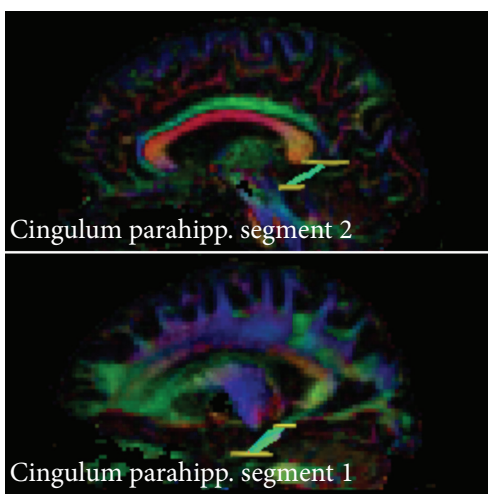

(d)
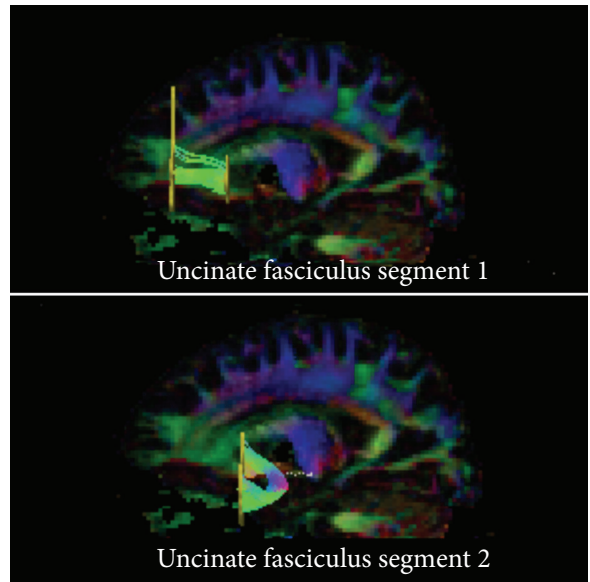

(g)

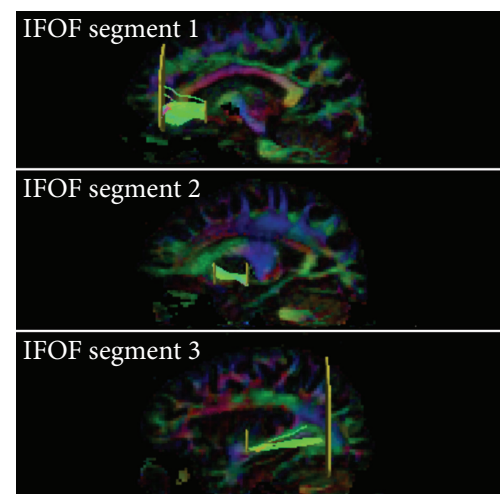

(b)

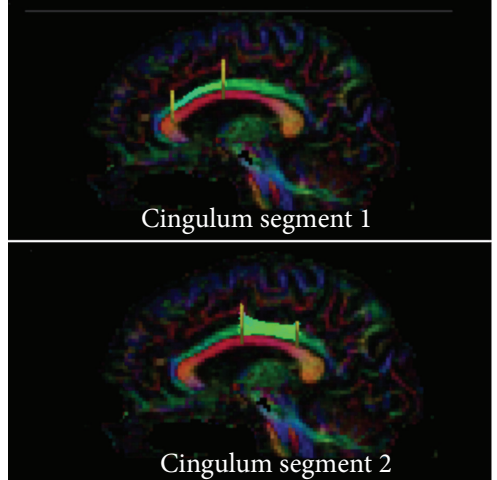

(c)

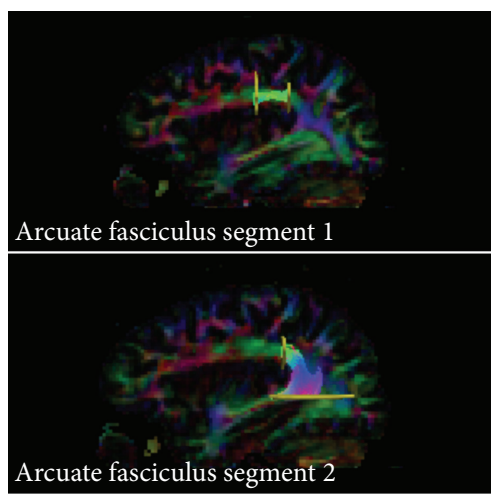

(e)

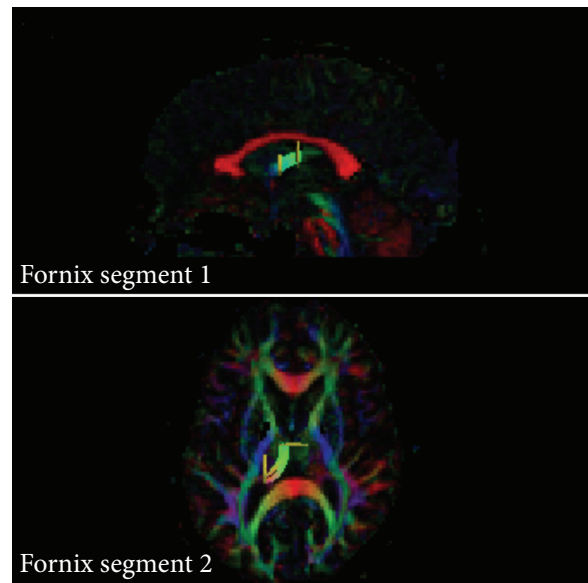

(h)

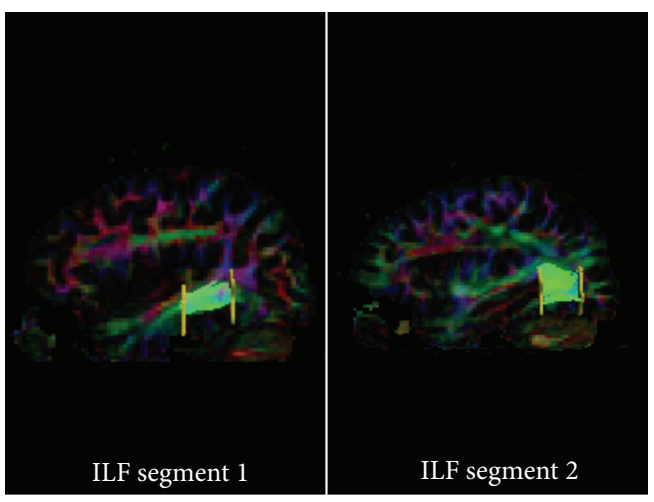

(f)

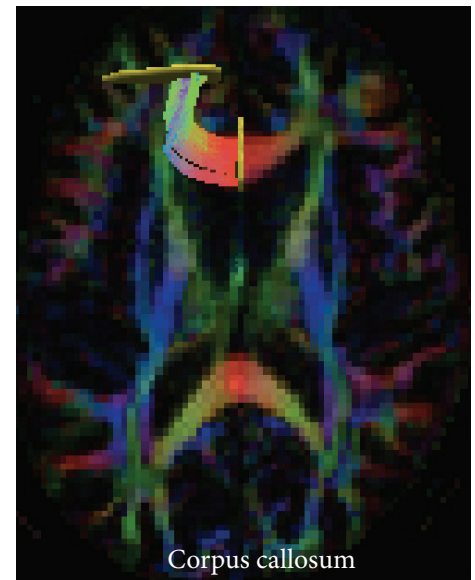

(i)

FIGURE 1: 3D-tractography in TrackVis in all tract segments in one patient, in the hemisphere contralateral to the tumor. (a) Corticospinal tract: segments 1-3. (b) Inferior frontooccipital fasciculus: segments 1-3. (c) Cingulum: segments 1 and 2. (d) Parahippocampal cingulum: segments 1 and 2. (e) Arcuate fasciculus: segments 1 and 2. (f) Inferior longitudinal fasciculus: segments 1 and 2. (g) Uncinate fasciculus: segments 1 and 2. (h) Fornix: segments 1 and 2. (i) Corpus callosum: forceps minor.

\section{Results}

Thirty-four patients had tumors appearing low-grade on morphological MRI without ( $n=24$ patients) or with $(n=10$ patients) patchy and faint contrast enhancement. Patient age at study entry was $48 \pm 15$ years (mean $\pm \mathrm{SD}$ ). The time between MRI and surgery was $3 \pm 7$ months (mean $\pm \mathrm{SD}$ ). The study population included 18 males and 16 females. Included patients had undergone presurgical radiological imaging, including morphological and physiological MRI with DTI (except for one patient, patient number 3, who had a biopsy 6 months prior to study MRI). Patients eligible for tractographic evaluation included in the statistical analysis were those with an astrocytoma $(n=18)$ or oligodendroglioma 


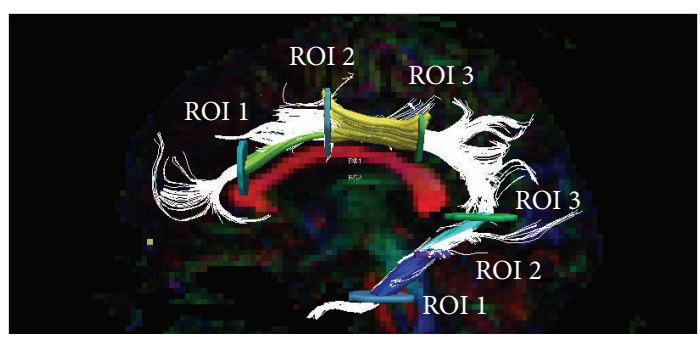

$\mathrm{L}$

Figure 2: Example tract of cingulum with ROIs and tract segments. The cingulum and the parahippocampal part of the cingulum visualized as a 3D-tract with associated ROIs and tract segments overlaid on 2D FA-color map. Whole tract visualized in white. Cingulum: segment 1 , green, and segment 2 , yellow. Parahippocampal cingulum: segment 1 , blue, and segment 2 , turquoise.

( $n=16$ ) grade II or III according to postoperative neuropathological reevaluation. Patients with diagnosis other than astrocytoma or oligodendroglioma grade II or III on neuropathological assessment or patients not yet operated on were not included in the analysis. Tractography was successfully performed in $98 \%$ of the tract segments (635 tract segments out of 646 , with 34 patients $\times 19$ tract segments $=$ 646). Technical details on tract segments regarding number of segments for each tract, segment length, and number of voxels per segment are presented in Supplementary Table 1. All segments except one were longer than $2 \mathrm{~cm}$. A total of 19 segments from nine tracts were evaluated with DTT in each patient (Figures 1(a)-1(i)). The total number of segments in all tracts in each hemisphere was 19 , and, out of these, 18 could be analyzed with rFA and rMD. rFA and rMD for segment one of the fornix could not be calculated because of its midline position.

3.1. Infiltration and Dislocation Based on Visual Assessment. On visual evaluation, 28 of the 34 included patients had at least one infiltrated tract segment (82\%). Seventeen of the 34 patients $(50 \%)$ had at least one dislocated tract segment. Thirteen of these 17 patients $(76 \%)$ had other tract segments that were infiltrated on visual evaluation. Details concerning tract segment infiltration and dislocation and tumor location are presented in Table 1.

Based on visual and quantitative evaluation, gliomas grade II and gliomas grade III had an equal propensity to infiltrate tract segments (chi-squared test, $p=0.75$ ) and showed similar diffusion alterations (Supplementary Table 2). Figures 3(a)-3(d) show an example of one infiltrated and one dislocated tract in two different patients.

3.2. Relative FA and MD Compared with Visual Assessment and Neuropathological Report (Glioma Type Astrocytoma or Oligodendroglioma, Glioma Grade II or III). rFA and rMD were calculated for all tract segments and compared between tract segments visually classified as infiltrated and those visually classified as not infiltrated. rFA was decreased in all tracts visually classified as infiltrated compared to those not classified as infiltrated, reaching statistical significance in all but two tract segments (89\%, 16/18 segments), Table 2 .

Similarly, rMD was higher in $89 \%$ of tract segments visually classified as infiltrated, reaching statistical significance in $78 \%$ (14/18 tract segments) (Table 3).

Figure 4 shows a box plot of rFA and rMD in tract segment infiltration.

rFA was higher in one dislocated tract segment compared to the contralateral not dislocated tract segment, $6 \%(1 / 18)$. Tumor involvement often included several lobes (Table 1). In the involved lobes, several tract segments were often dislocated or infiltrated (Table 1). Furthermore, rFA and rMD were compared with neuropathological (glioma types astrocytoma and oligodendroglioma, glioma grades II and III) and radiological (visual tract segment dislocation or not, hemisphere location in right or left hemisphere) features. Detailed results from all comparisons are presented in Supplementary Table 2. rFA and rMD in tract segments did not differ significantly between gliomas grade II and gliomas grade III. Significant differences were found between $\mathrm{rFA}$ and rMD between astrocytomas (lower FA and higher MD) and oligodendrogliomas in $22 \%$ of all evaluated tract segments (4/18).

\section{Discussion}

Preoperative DTT evaluation of suspected tumor infiltration is increasingly required by the neurosurgeons, but it has not yet become a clinical routine procedure in every neuroradiological center. The method has been validated in normal populations but needs further evaluation in patients with suspected glioma to prove its clinical value [35]. We systematically assessed major associative, projection, and commissural bundles and compared quantitative analysis of tract segments with visual tract evaluation and neuropathological diagnosis in patients with nonnecrotic gliomas grades II and III. We divided the tracts into segments in order to improve the detection of partial tract infiltration.

Previous studies have reported on the usefulness of tractography for preoperative assessment of glioma infiltration along tracts with regard to surgical planning [11, 31]. Retrospective evaluation of gliomas has shown longer survival in patients with noninfiltrative gliomas [21, 47]. No prospective study has to our knowledge evaluated DTT in a cohort of prospectively included suspected low-grade gliomas. Our main finding was that radiological suspicion of glioma infiltration on visual evaluation was confirmed by significantly reduced $\mathrm{rFA}$ in $89 \%(16 / 18)$ of the evaluated tract segments. $11 \%(2 / 18)$ had lower $\mathrm{rFA}$ but did not reach statistical significance. In segment two of the fornix only two out of 32 patients had visual infiltration making the comparison less likely to show statistical significance. In consistency with earlier reports, dislocated tract segments had no significant alterations of rFA or rMD in $94 \%$ compared with not dislocated tract segments, Supplementary Table 2.

Reduced FA in tumor-infiltrated white matter regions is the most studied finding related to DTI tumor evaluation. Supported by DTI experiment in rat glioma models, reduced 


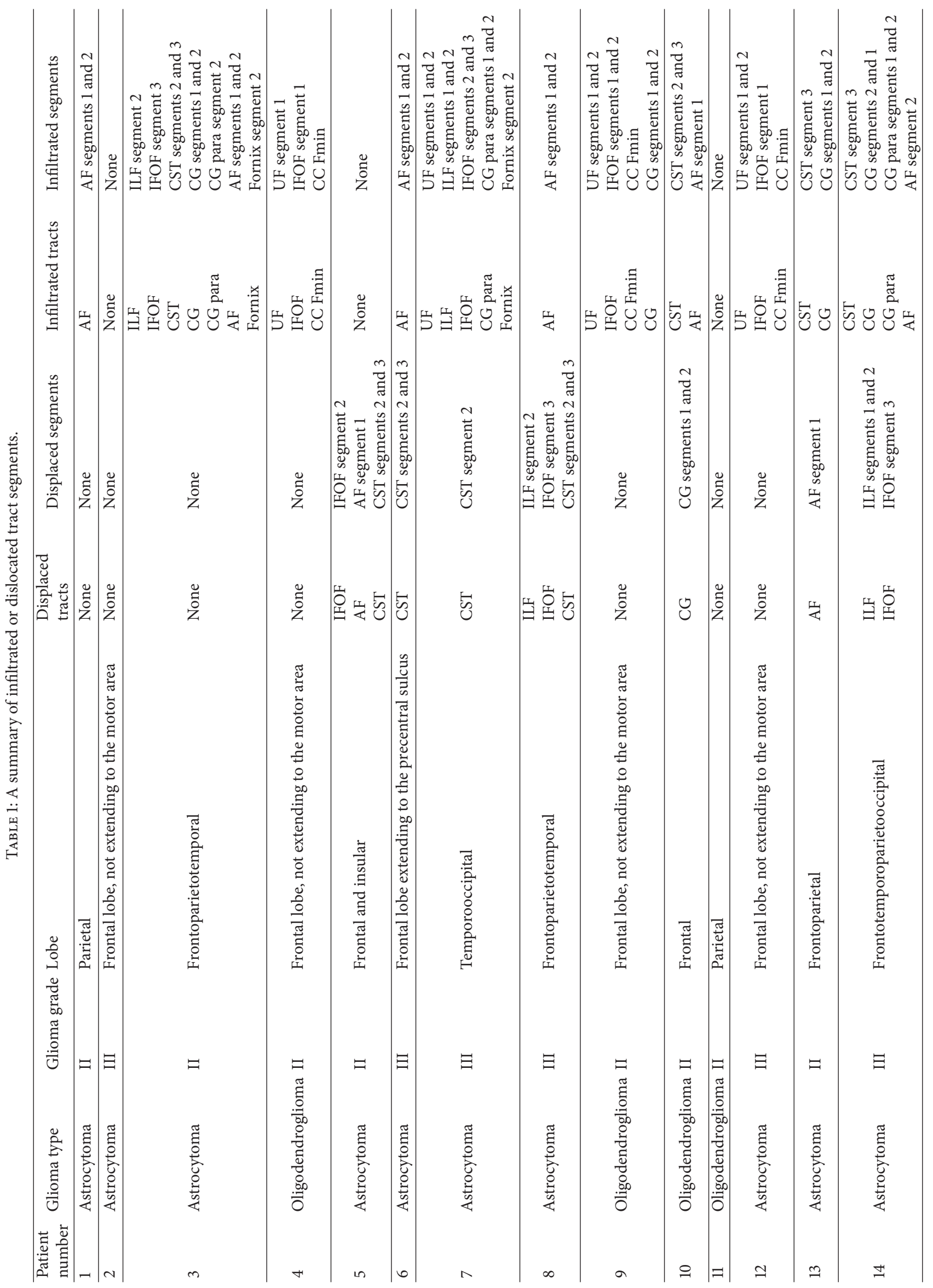




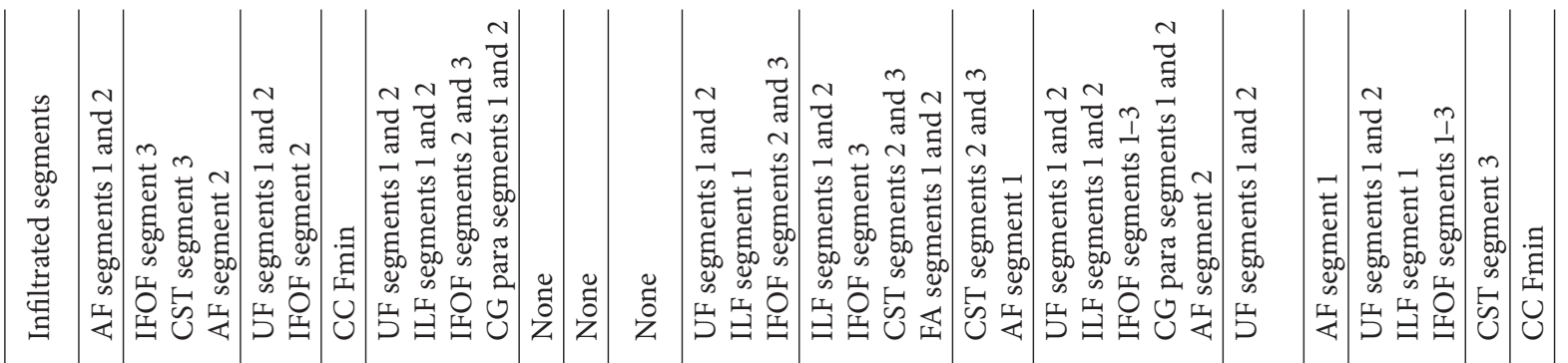

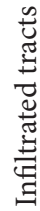

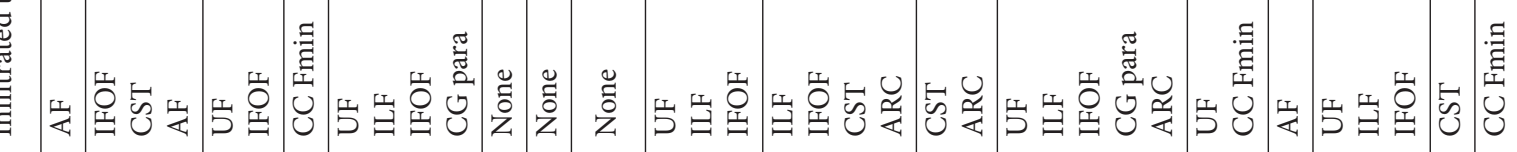

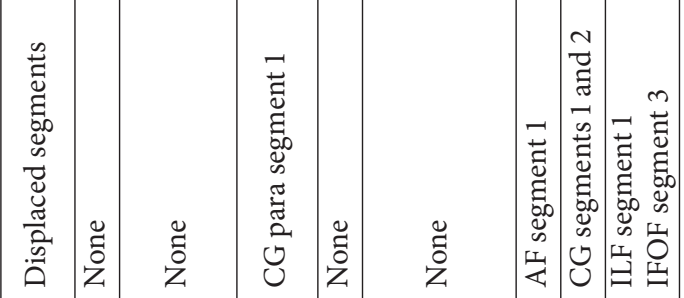

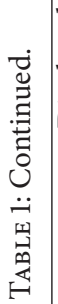

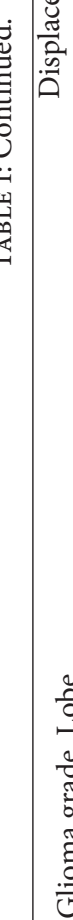

\section{(a)}

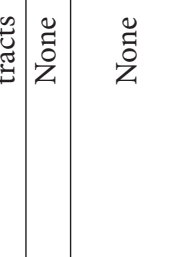

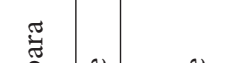

\begin{abstract}
(
\end{abstract}
Uે
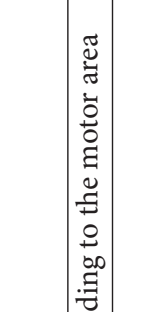

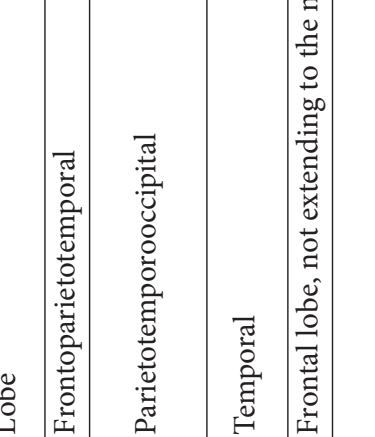

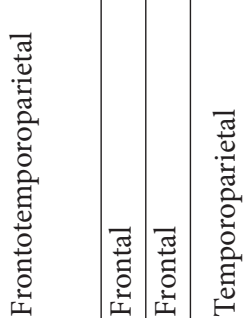

\section{5}

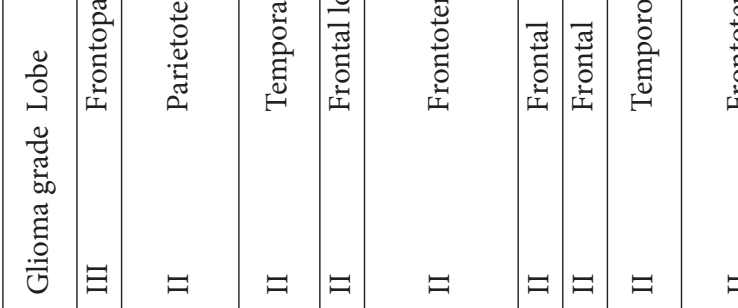

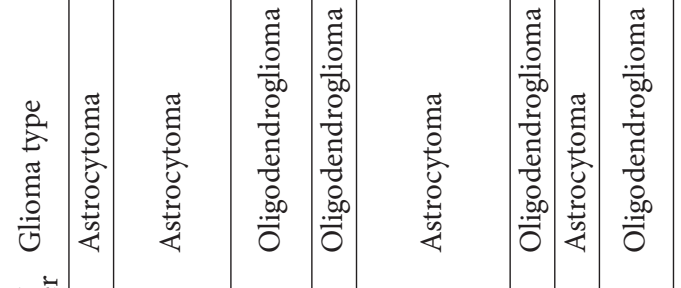

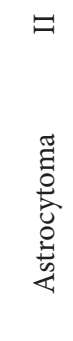

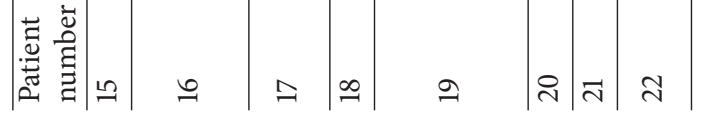

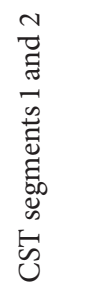

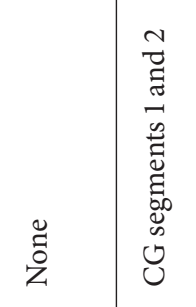

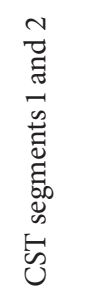

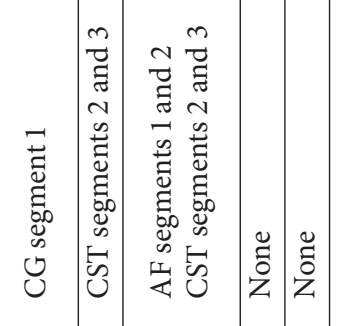

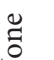

$\circlearrowleft$

s

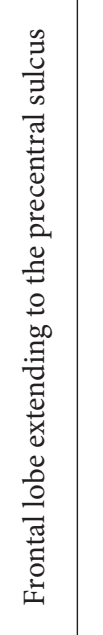

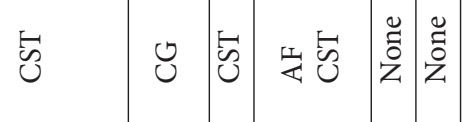
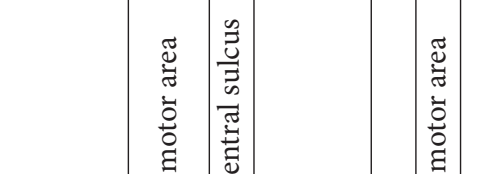

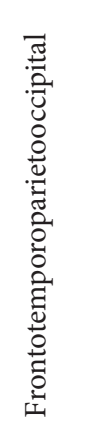

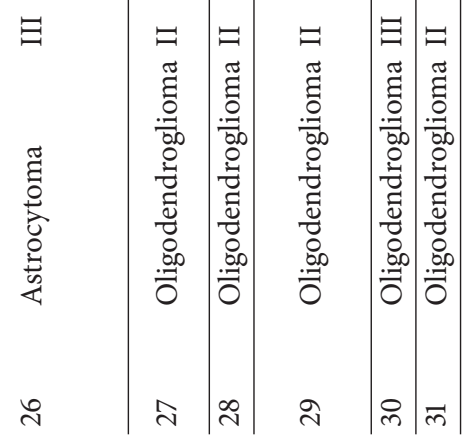




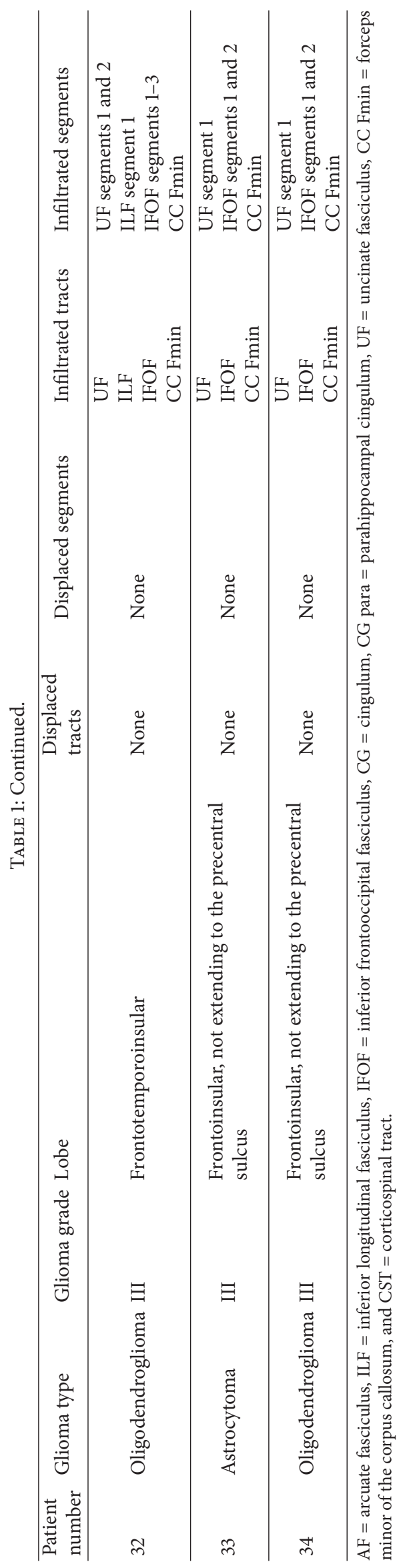




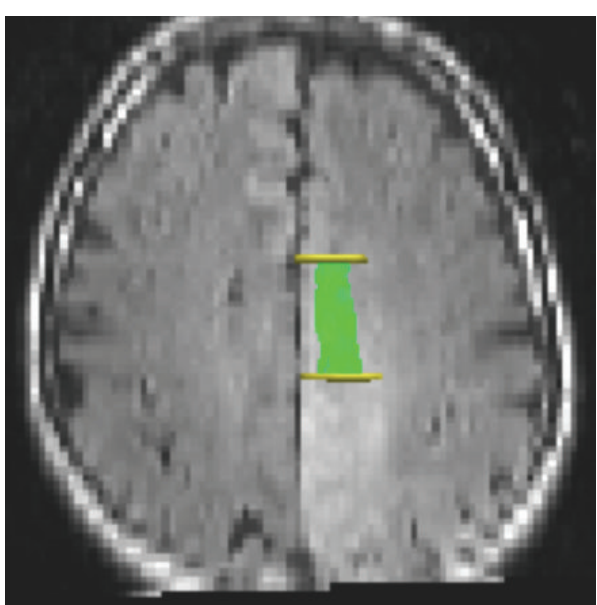

(a)

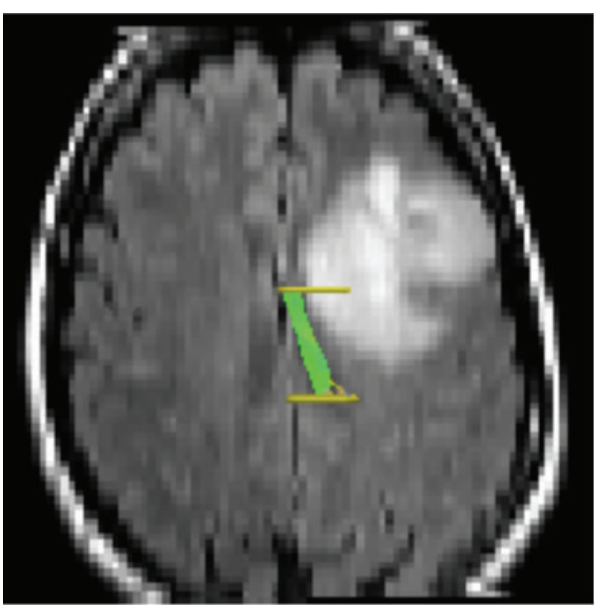

(c)

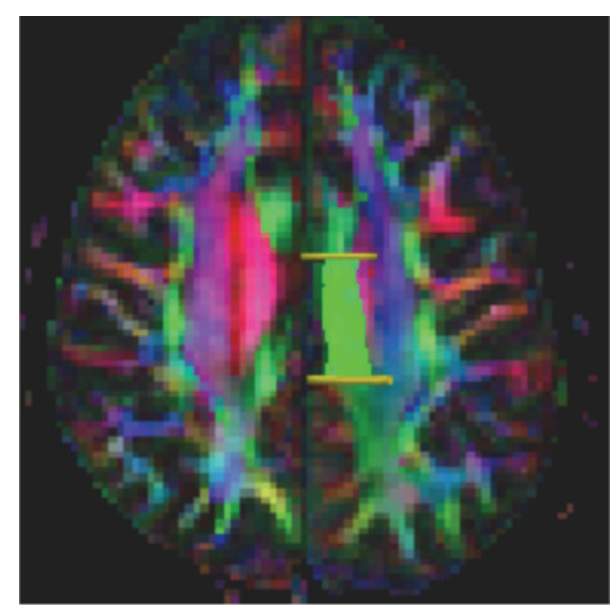

(b)

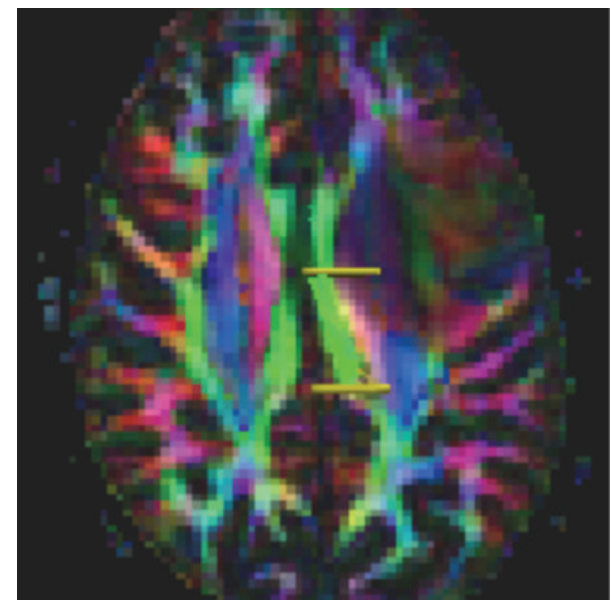

(d)

FIgURE 3: Tractography of segment 2 of the cingulum in two different patients (patient number 14 and patient number 25). ((a)-(b)) Patient with an astrocytoma grade III. (a) 3D-tractography of segment 2 of the cingulum overlaid on T2-FLAIR image shows tumor infiltrating the area of the tract segment. ROIs number two and three in yellow. (b) 3D-tractography in the same patient, segment two of the cingulum overlaid on 2D FA-color map. ((c)-(d)) Patient with an oligodendroglioma grade II. (c) 3D-tractography of segment 2 of the cingulum overlaid on T2-FLAIR image shows tumor dislocation of the tract segment. ROIs number two and three in yellow. (d) 3D-tractography in the same patient, segment two of the cingulum overlaid on 2D FA-color map.

rFA in investigated tract segments indicates glioma growth [19]. In general, rFA and rMD in tract segments showed a poor association with glioma grade and type in our study. Gliomas grades II and III had an equal distribution of visual tract segment infiltration, highlighting the intrinsic propensity for infiltrative growth in both tumor grades.

In consistency with earlier reports on glioma infiltration and dislocation of tracts, several patients had infiltration of some tracts combined with dislocation of others [47]. Why gliomas infiltrate some tracts and dislocate others has still to be elucidated. The vulnerability of specific white matter tracts, tumor location, neuropathological glioma characteristics, and progressive disease or tumor volume could all play a role in the processes that influence gliomas growth.

Suspected low-grade gliomas share common imaging criteria: no or patchy and faint contrast enhancement, no extensive mass effect, and no edema. These inclusion criteria, as well as earlier studies showing that low-grade gliomas are mainly confined within the hyperintensity on T2-weighted images, support that our findings of lower rFA and higher rMD in infiltrated segments are related to tumor growth, and not edema. The fact that these tumors (suspected lowgrade) do not exhibit surrounding edema makes the changes in diffusion found in visually infiltrated tracts most likely due to bulk tumor infiltration.

The strengths of this study are attributed to the extensive analysis of 19 segments in nine white matter pathways in a prospectively gathered cohort of patients with suspected low-grade gliomas. Segment-wise tractography rather than averaging across a whole tract increases the regional specificity. All patients included in the analysis had a confirmed 
TABLE 2: Results from tractography, fractional anisotropy.

\begin{tabular}{|c|c|c|c|c|c|c|c|c|c|}
\hline Track & & Corticospinal tract & $p$ & & Corticospinal tract & $p$ & & Corticospinal tract & $p$ \\
\hline DTI scalars & & rFA mean $(\mathrm{SD})$ & \multirow{4}{*}{0.006135} & & rFA mean $(\mathrm{SD})$ & \multirow{4}{*}{0.021797} & & rFA mean $(\mathrm{SD})$ & \multirow{4}{*}{0.138} \\
\hline Segment & & Segment 1 & & & Segment 2 & & & Segment 3 & \\
\hline $\begin{array}{l}\text { Infiltrated tract } \\
\text { segment }\end{array}$ & $n=8$ & $0.96(0.03)$ & & $n=8$ & $0.93(0.06)$ & & $n=8$ & $0.95(0.08)$ & \\
\hline $\begin{array}{l}\text { Not infiltrated tract } \\
\text { segment }\end{array}$ & $n=26$ & $1.01(0.05)$ & & $n=26$ & $1.00(0.06)$ & & $n=26$ & $1.01(0.08)$ & \\
\hline Track & & $\begin{array}{c}\text { Inferior } \\
\text { frontooccipital } \\
\text { fasciculus }\end{array}$ & $p$ & & $\begin{array}{c}\text { Inferior } \\
\text { frontooccipital } \\
\text { fasciculus }\end{array}$ & $p$ & & $\begin{array}{c}\text { Inferior } \\
\text { frontooccipital } \\
\text { fasciculus }\end{array}$ & $p$ \\
\hline DTI scalars & & rFA mean $(\mathrm{SD})$ & \multirow{4}{*}{0.00029} & & rFA mean (SD) & \multirow{4}{*}{0.000027} & & rFA mean (SD) & \multirow{4}{*}{0.000218} \\
\hline Segment & & Segment 1 & & & Segment 2 & & & Segment 3 & \\
\hline $\begin{array}{l}\text { Infiltrated tract } \\
\text { segment }\end{array}$ & $n=14$ & $0.80(0.14)$ & & $n=15$ & $0.74(0.16)$ & & $n=14$ & $0.89(0.11)$ & \\
\hline $\begin{array}{l}\text { Not infiltrated tract } \\
\text { segment }\end{array}$ & $n=19$ & $0.99(0.07)$ & & $n=19$ & $0.98(0.08)$ & & $n=19$ & $1.03(0.06)$ & \\
\hline Track & & Cingulum & $p$ & & Cingulum & $p$ & & & \\
\hline DTI scalars & & rFA mean (SD) & \multirow{4}{*}{0.004241} & & rFA mean (SD) & \multirow{4}{*}{0.001471} & & & \\
\hline Segment & & Segment 1 & & & Segment 2 & & & & \\
\hline $\begin{array}{l}\text { Infiltrated tract } \\
\text { segment }\end{array}$ & $n=4$ & $0.64(0.16)$ & & $n=4$ & $0.58(0.22)$ & & & & \\
\hline $\begin{array}{l}\text { Not infiltrated tract } \\
\text { segment }\end{array}$ & $n=30$ & $1.02(0.17)$ & & $n=30$ & $1.03(0.07)$ & & & & \\
\hline Track & & $\begin{array}{l}\text { Parahippocampal } \\
\text { cg }\end{array}$ & $p$ & & $\begin{array}{l}\text { Parahippocampal } \\
\text { cg }\end{array}$ & $p$ & & & \\
\hline DTI scalars & & rFA mean (SD) & \multirow{4}{*}{0.002188} & & rFA mean (SD) & \multirow{4}{*}{0.000463} & & & \\
\hline Segment & & Segment 1 & & & Segment 2 & & & & \\
\hline $\begin{array}{l}\text { Infiltrated tract } \\
\text { segment }\end{array}$ & $n=5$ & $0.61(0.21)$ & & $n=5$ & $0.55(0.14)$ & & & & \\
\hline $\begin{array}{l}\text { Not infiltrated tract } \\
\text { segment }\end{array}$ & $n=29$ & $0.98(0.10)$ & & $n=29$ & $0.98(0.11)$ & & & & \\
\hline Track & & Arcuate fasciculus & $p$ & & Arcuate fasciculus & $p$ & & & \\
\hline DTI scalars & & rFA mean $(\mathrm{SD})$ & \multirow{4}{*}{0.000386} & & rFA mean $(\mathrm{SD})$ & \multirow{4}{*}{0.000026} & & & \\
\hline Segment & & Segment 1 & & & Segment 2 & & & & \\
\hline $\begin{array}{l}\text { Infiltrated tract } \\
\text { segment }\end{array}$ & $n=12$ & $0.76(0.16)$ & & $n=10$ & $0.76(0.11)$ & & & & \\
\hline $\begin{array}{l}\text { Not infiltrated tract } \\
\text { segment }\end{array}$ & $n=22$ & $0.98(0.06)$ & & $n=21$ & $1.00(0.07)$ & & & & \\
\hline Track & & $\begin{array}{c}\text { Inferior } \\
\text { longitudinal } \\
\text { fasciculus }\end{array}$ & $p$ & & $\begin{array}{c}\text { Inferior } \\
\text { longitudinal } \\
\text { fasciculus }\end{array}$ & $p$ & & & \\
\hline DTI scalars & & rFA mean (SD) & \multirow{4}{*}{0.000173} & & rFA mean (SD) & \multirow{4}{*}{0.000173} & & & \\
\hline Segment & & Segment 1 & & & Segment 2 & & & & \\
\hline $\begin{array}{l}\text { Infiltrated tract } \\
\text { segment }\end{array}$ & $n=8$ & $0.75(0.18)$ & & $n=8$ & $0.84(0.09)$ & & & & \\
\hline $\begin{array}{l}\text { Not infiltrated tract } \\
\text { segment }\end{array}$ & $n=26$ & $0.99(0.08)$ & & $n=26$ & $1.00(0.07)$ & & & & \\
\hline Track & & Uncinate fasciculus & \multirow{5}{*}{0.000003} & & Uncinate fasciculus & $p$ & & & \\
\hline DTI scalars & & rFA mean $(\mathrm{SD})$ & & & rFA mean $(\mathrm{SD})$ & \multirow{4}{*}{0.001058} & & & \\
\hline Segment & & Segment 1 & & & Segment 2 & & & & \\
\hline $\begin{array}{l}\text { Infiltrated tract } \\
\text { segment }\end{array}$ & $n=12$ & $0.76(0.09)$ & & $n=12$ & $0.77(0.18)$ & & & & \\
\hline $\begin{array}{l}\text { Not infiltrated tract } \\
\text { segment }\end{array}$ & $n=21$ & $1.01(0.08)$ & & $n=21$ & $1.00(0.10)$ & & & & \\
\hline
\end{tabular}


TABLE 2: Continued.

\begin{tabular}{|c|c|c|c|c|c|c|}
\hline Track & & Fornix & $p$ & & Fornix & $p$ \\
\hline DTI scalars & & FA ratio & & & rFA mean (SD) & \multirow{4}{*}{0.056} \\
\hline Segment & & 1 , midline & & & Segment 2 & \\
\hline $\begin{array}{l}\text { Infiltrated tract } \\
\text { segment }\end{array}$ & $\mathrm{NA}^{*}$ & $\mathrm{NA}^{*}$ & $\mathrm{NA}^{*}$ & $n=2$ & $0.88(0.10)$ & \\
\hline $\begin{array}{l}\text { Not infiltrated tract } \\
\text { segment }\end{array}$ & $\mathrm{NA}^{*}$ & $\mathrm{NA}^{*}$ & $\mathrm{NA}^{*}$ & $n=30$ & $1.02(0.09)$ & \\
\hline Track & & $\begin{array}{l}\text { Callosal body } \\
\text { minor forceps }\end{array}$ & $p$ & & & \\
\hline DTI scalars & & rFA mean (SD) & \multirow{4}{*}{0.00301} & & & \\
\hline Segment & & Segment 1 & & & & \\
\hline $\begin{array}{l}\text { Infiltrated tract } \\
\text { segment }\end{array}$ & $n=9$ & $0.88(0.12)$ & & & & \\
\hline $\begin{array}{l}\text { Not infiltrated tract } \\
\text { segment }\end{array}$ & $n=25$ & $1.01(0.05)$ & & & & \\
\hline
\end{tabular}

* No ratio due to tract segment in midline.

rFA in infiltrated and not infiltrated tract segment presented as mean and standard deviation with results from Mann-Whitney $U$ tests. $p<0.05$ was regarded as statistically significant.

$\mathrm{rFA}=$ relative fractional anisotropy (ipsilateral mean FA/contralateral mean FA), $\mathrm{SD}=$ standard deviation, $\mathrm{cg}=\mathrm{cingulum}$, and $\mathrm{NA}=$ not available

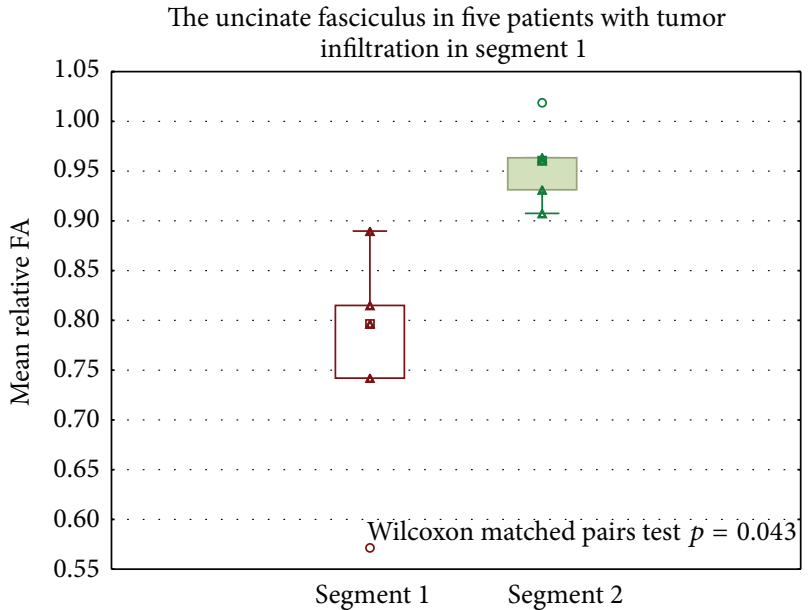

FIGURE 4: Box plot of rFA in tract segments. rFA in segments 1 and 2 in the uncinate fasciculus, in five patients with tumor infiltration in segment 1 . Significantly lower $r F A$ in segment 1 compared to segment 2. Wilcoxon matched pairs test, $p=0.043 . \mathrm{rFA}=$ relative fractional anisotropy.

neuropathological diagnosis of astrocytoma or oligodendroglioma grade II or grade III.

Preoperative knowledge about suspected tumor tract infiltration and tumor tract dislocation can aid surgical preoperative planning and indicates the need for an extended preoperative evaluation including also neurophysiological assessment. It might also aid upon informing the patient about the expected neurological outcome after surgery, which may depend on the extent of tract involvement.

Based on our findings, future studies evaluating measurement of diffusion properties in multiple tract segments may provide new important information about the extent of glioma infiltration. Future applications of this method might also give insight into tract segment infiltration related to different histological subtypes of gliomas.
We acknowledge three major limitations of the present study. First, the limited number of patients included in this study is a disadvantage in a study of heterogeneous tumors with different locations in the brain. Small differences in subgroups can be missed, and our findings need to be interpreted with care and need confirmation in larger cohorts [32]. However, the results on diffusion changes in visually infiltrated tract segments were a consistent finding over different patients and different tracts segments.

Second, infiltrated tracts were visually classified based on T2-FLAIR and FA-color maps; however, this study lacks neuropathological verifications of these findings. To evaluate the visual assessment of tract segment infiltration we compared the results from visual analysis with quantitative data from tract segments. In support of our findings regarding low rFA in infiltrated tract segments, Stadlbauer et al. 2007 showed an association between lower FA values and increasing tumor cell numbers [48].

The third limitation concerns the tractography method. A weakness of the DTT technique is the difficulty of successful tractography in regions with crossing fibers $[49,50]$. We strove to minimize this influence by avoiding tracts and segments with known difficulties when deterministic tractography is used. In the segmentation of the tracts, we balanced segment length and tractography quality, and, thus, a majority of investigated tracts (7/9) comprised two segments. This limited the possibility of studying variation in FA and MD along tracts and at different distances from the tumor. Also, FA is affected by both white matter integrity and orientation dispersion and methods to separate the two have been devised recently but require high $b$-value data [51].

Since intraoperative subcortical mapping using direct electrical stimulations under awake surgery is the gold standard to directly visualize the subcortical connectivity future DTT studies should be compared with intraoperative observation of subcortical tracts [9]. 
TABLE 3: Results from tractography, mean diffusivity.

\begin{tabular}{|c|c|c|c|c|c|c|c|c|c|}
\hline Track & & Corticospinal tract & $p$ & & Corticospinal tract & $p$ & & Corticospinal tract & $p$ \\
\hline DTI scalars & & rMD mean $(\mathrm{SD})$ & \multirow{4}{*}{0.383} & & rMD mean (SD) & \multirow{4}{*}{0.761} & & rMD mean $(\mathrm{SD})$ & \multirow{4}{*}{0.009935} \\
\hline Segment & & Segment 1 & & & Segment 2 & & & Segment 3 & \\
\hline $\begin{array}{l}\text { Infiltrated tract } \\
\text { segment }\end{array}$ & $n=8$ & $0.98(0.05)$ & & $n=8$ & $1.01(0.04)$ & & $n=8$ & $1.08(0.10)$ & \\
\hline $\begin{array}{l}\text { Not infiltrated tract } \\
\text { segment }\end{array}$ & $n=26$ & $0.99(0.04)$ & & $n=26$ & $1.01(0.04)$ & & $n=26$ & $1.00(0.04)$ & \\
\hline Track & & $\begin{array}{c}\text { Inferior } \\
\text { frontooccipital } \\
\text { fasciculus } \\
\end{array}$ & $p$ & & $\begin{array}{c}\text { Inferior } \\
\text { frontooccipital } \\
\text { fasciculus }\end{array}$ & $p$ & & $\begin{array}{c}\text { Inferior } \\
\text { frontooccipital } \\
\text { fasciculus } \\
\end{array}$ & $p$ \\
\hline DTI scalars & & rMD mean $(\mathrm{SD})$ & \multirow{4}{*}{0.000122} & & rMD mean $(\mathrm{SD})$ & \multirow{4}{*}{0.009287} & & rMD mean $(\mathrm{SD})$ & \multirow{4}{*}{0.018801} \\
\hline Segment & & Segment 1 & & & Segment 2 & & & Segment 3 & \\
\hline $\begin{array}{l}\text { Infiltrated tract } \\
\text { segment }\end{array}$ & $n=14$ & $1.19(0.21)$ & & $n=15$ & $1.20(0.26)$ & & $n=14$ & $1.07(0.09)$ & \\
\hline $\begin{array}{l}\text { Not infiltrated tract } \\
\text { segment }\end{array}$ & $n=19$ & $1.00(0.02)$ & & $n=19$ & $1.01(0.04)$ & & $n=19$ & $0.99(0.06)$ & \\
\hline Track & & Cingulum & $p$ & & Cingulum & $p$ & & & \\
\hline DTI scalars & & rMD mean $(\mathrm{SD})$ & \multirow{4}{*}{0.002116} & & rMD mean $(\mathrm{SD})$ & \multirow{4}{*}{0.001471} & & & \\
\hline Segment & & Segment 1 & & & Segment 2 & & & & \\
\hline $\begin{array}{l}\text { Infiltrated tract } \\
\text { segment }\end{array}$ & $n=4$ & $1.19(0.15)$ & & $n=4$ & $1.47(0.55)$ & & & & \\
\hline $\begin{array}{l}\text { Not infiltrated tract } \\
\text { segment }\end{array}$ & $n=30$ & $1.03(0.04)$ & & $n=30$ & $1.01(0.04)$ & & & & \\
\hline Track & & $\begin{array}{c}\text { Parahippocampal } \\
\text { cg }\end{array}$ & $p$ & & $\begin{array}{c}\text { Parahippocampal } \\
\text { cg }\end{array}$ & $p$ & & & \\
\hline DTI scalars & & rMD mean $(\mathrm{SD})$ & \multirow{4}{*}{0.001574} & & rMD mean $(\mathrm{SD})$ & \multirow{4}{*}{0.000793} & & & \\
\hline Segment & & Segment 1 & & & Segment 2 & & & & \\
\hline $\begin{array}{l}\text { Infiltrated tract } \\
\text { segment }\end{array}$ & $n=5$ & $1.44(0.34)$ & & $n=5$ & $1.37(0.25)$ & & & & \\
\hline $\begin{array}{l}\text { Not infiltrated tract } \\
\text { segment }\end{array}$ & $n=29$ & $1.03(0.10)$ & & $n=29$ & $1.01(0.08)$ & & & & \\
\hline Track & & Arcuate fasciculus & $p$ & & Arcuate fasciculus & $p$ & & & \\
\hline DTI scalars & & rMD mean $(\mathrm{SD})$ & \multirow{4}{*}{0.000166} & & rMD mean $(\mathrm{SD})$ & \multirow{4}{*}{0.001226} & & & \\
\hline Segment & & Segment 1 & & & Segment 2 & & & & \\
\hline $\begin{array}{l}\text { Infiltrated tract } \\
\text { segment }\end{array}$ & $n=12$ & $1.34(0.28)$ & & $n=10$ & $1.22(0.21)$ & & & & \\
\hline $\begin{array}{l}\text { Not infiltrated tract } \\
\text { segment }\end{array}$ & $n=22$ & $1.00(0.04)$ & & $n=21$ & $1.01(0.04)$ & & & & \\
\hline Track & & $\begin{array}{c}\text { Inferior } \\
\text { longitudinal } \\
\text { fasciculus }\end{array}$ & $p$ & & $\begin{array}{c}\text { Inferior } \\
\text { longitudinal } \\
\text { fasciculus } \\
\end{array}$ & $p$ & & & \\
\hline DTI scalars & & rMD mean $(\mathrm{SD})$ & \multirow{4}{*}{0.000602} & & rMD mean $(\mathrm{SD})$ & \multirow{4}{*}{0.002844} & & & \\
\hline Segment & & Segment 1 & & & Segment 2 & & & & \\
\hline $\begin{array}{l}\text { Infiltrated tract } \\
\text { segment }\end{array}$ & $n=8$ & $1.19(0.15)$ & & $n=8$ & $1.11(0.11)$ & & & & \\
\hline $\begin{array}{l}\text { Not infiltrated tract } \\
\text { segment }\end{array}$ & $n=26$ & $1.01(0.04)$ & & $n=26$ & $1.00(0.06)$ & & & & \\
\hline Track & & Uncinate fasciculus & \multirow{5}{*}{0.000146} & & Uncinate fasciculus & $p$ & & & \\
\hline DTI scalars & & rMD mean $(\mathrm{SD})$ & & & rMD mean $(\mathrm{SD})$ & \multirow{4}{*}{0.15} & & & \\
\hline Segment & & Segment 1 & & & Segment 2 & & & & \\
\hline $\begin{array}{l}\text { Infiltrated tract } \\
\text { segment }\end{array}$ & $n=12$ & $1.18(0.15)$ & & $n=12$ & $1.24(0.27)$ & & & & \\
\hline $\begin{array}{l}\text { Not infiltrated tract } \\
\text { segment }\end{array}$ & $n=21$ & $1.01(0.03)$ & & $n=21$ & $1.01(0.04)$ & & & & \\
\hline
\end{tabular}


TABLE 3: Continued.

\begin{tabular}{|c|c|c|c|c|c|c|}
\hline Track & & Fornix & $p$ & & Fornix & $p$ \\
\hline DTI scalars & & rMD mean (SD) & & & rMD mean (SD) & \multirow{4}{*}{0.371} \\
\hline Segment & & 1, midline & & & Segment 2 & \\
\hline $\begin{array}{l}\text { Infiltrated tract } \\
\text { segment }\end{array}$ & $\mathrm{NA}^{*}$ & $\mathrm{NA}^{*}$ & $\mathrm{NA}^{*}$ & $n=2$ & $1.09(0.02)$ & \\
\hline $\begin{array}{l}\text { Not infiltrated tract } \\
\text { segment }\end{array}$ & $\mathrm{NA}^{*}$ & $\mathrm{NA}^{*}$ & $\mathrm{NA}^{*}$ & $n=30$ & $1.03(0.19)$ & \\
\hline Track & & $\begin{array}{l}\text { Callosal body } \\
\text { minor forceps }\end{array}$ & $p$ & & & \\
\hline DTI scalars & & rMD mean (SD) & \multirow{4}{*}{0.000209} & & & \\
\hline Segment & & Segment 1 & & & & \\
\hline $\begin{array}{l}\text { Infiltrated tract } \\
\text { segment }\end{array}$ & $n=9$ & $1.13(0.08)$ & & & & \\
\hline $\begin{array}{l}\text { Not infiltrated tract } \\
\text { segment }\end{array}$ & $n=25$ & $1.01(0.02)$ & & & & \\
\hline
\end{tabular}

* No ratio due to tract segment in midline.

rMD in infiltrated and not infiltrated tract segment presented as mean and standard deviation with results from Mann-Whitney $U$ tests. $p<0.05$ was regarded as statistically significant.

$\mathrm{rMD}=$ relative mean diffusivity (ipsilateral mean diffusivity/contralateral mean diffusivity), $\mathrm{SD}=$ standard deviation, $\mathrm{cg}=\mathrm{cingulum}$, and $\mathrm{NA}=$ not available.

\section{Conclusion}

Quantitative MR tractography is applicable in patients with nonnecrotic gliomas grades II and III and corresponds to visual evaluation of suspected tract infiltration. It is thus a promising objective tool for the preoperative evaluation of tract segment involvement in these tumors.

\section{Abbreviations \\ rFA: Relative fractional anisotropy \\ rMD: Relative mean diffusivity \\ DTT: Diffusion tensor tractography \\ DTI: Diffusion tensor imaging \\ ROI: Region of interest.}

\section{Competing Interests}

The authors declare that they have no competing interests.

\section{Authors' Contributions}

All authors participated in the study design: Johanna Mårtensson, Jimmy Lätt, and Markus Nilsson postprocessed the data; Anna F. Delgado performed the tractography and statistical analyses and drafted the paper. All authors critically revised the paper and approved the final version.

\section{Acknowledgments}

Uppsala county council has provided financial support for the study. Grant from Swedish Cancer Society was received.

\section{References}

[1] M. L. Goodenberger and R. B. Jenkins, "Genetics of adult glioma," Cancer Genetics, vol. 205, no. 12, pp. 613-621, 2012.
[2] D. N. Louis, H. Ohgaki, O. D. Wiestler et al., "The 2007 WHO classification of tumours of the central nervous system," Acta Neuropathologica, vol. 114, no. 2, pp. 97-109, 2007.

[3] M. Waqar, S. Hanif, A. R. Brodbelt et al., "Prognostic factors in lobar world health organization grade II astrocytomas," World Neurosurgery, vol. 84, no. 1, pp. 154-162, 2015.

[4] J. Pallud, L. Capelle, L. Taillandier et al., "Prognostic significance of imaging contrast enhancement for WHO grade II gliomas," Neuro-Oncology, vol. 11, no. 2, pp. 176-182, 2009.

[5] R. Dubrow and A. S. Darefsky, "Demographic variation in incidence of adult glioma by subtype, United States, 1992-2007," BMC Cancer, vol. 11, article 325, 2011.

[6] K. Gousias, J. Schramm, and M. Simon, "Extent of resection and survival in supratentorial infiltrative low-grade gliomas: analysis of and adjustment for treatment bias," Acta Neurochirurgica, vol. 156, no. 2, pp. 327-337, 2014.

[7] L. Capelle, D. Fontaine, E. Mandonnet et al., "Spontaneous and therapeutic prognostic factors in adult hemispheric World Health Organization Grade II gliomas: a series of 1097 cases," Journal of Neurosurgery, vol. 118, no. 6, pp. 1157-1168, 2013.

[8] J. Pallud, P. Varlet, B. Devaux et al., "Diffuse low-grade oligodendrogliomas extend beyond MRI-defined abnormalities," Neurology, vol. 74, no. 21, pp. 1724-1731, 2010.

[9] J. Boetto, L. Bertram, G. Moulinié, G. Herbet, S. Moritz-Gasser, and H. Duffau, "Low rate of intraoperative seizures during awake craniotomy in a prospective cohort with 374 supratentorial brain lesions: electrocorticography is not mandatory," World Neurosurgery, vol. 84, no. 6, pp. 1838-1844, 2015.

[10] Z. Farshidfar, F. Faeghi, M. Mohseni, A. Seddighi, H. H. Kharrazi, and J. Abdolmohammadi, "Diffusion tensor tractography in the presurgical assessment of cerebral gliomas," Neuroradiology Journal, vol. 27, no. 1, pp. 75-84, 2014.

[11] A. Castellano, L. Bello, C. Michelozzi et al., "Role of diffusion tensor magnetic resonance tractography in predicting the extent of resection in glioma surgery," Neuro-Oncology, vol. 14, no. 2, pp. 192-202, 2012.

[12] L. Bello, A. Gambini, A. Castellano et al., "Motor and language DTI Fiber Tracking combined with intraoperative subcortical 
mapping for surgical removal of gliomas," NeuroImage, vol. 39, no. 1, pp. 369-382, 2008.

[13] Y. N. Yordanova, S. Moritz-Gasser, and H. Duffau, "Awake surgery for WHO grade II gliomas within 'noneloquent' areas in the left dominant hemisphere: toward a 'supratotal' resection. Clinical article," Journal of Neurosurgery, vol. 115, no. 2, pp. 232239, 2011.

[14] J. A. Wilden, J. Voorhies, K. M. Mosier, D. P. O’Neill, and A. A. Cohen-Gadol, "Strategies to maximize resection of complex, or high surgical risk, low-grade gliomas," Neurosurgical Focus, vol. 34, no. 2, article E5, 2013.

[15] B. L. Dean, B. P. Drayer, C. R. Bird et al., "Gliomas: classification with MR imaging," Radiology, vol. 174, no. 2, pp. 411-415, 1990.

[16] M.-L. Schäfer, M. H. Maurer, M. Synowitz et al., "Low-grade (WHO II) and anaplastic (WHO III) gliomas: differences in morphology and MRI signal intensities," European Radiology, vol. 23, no. 10, pp. 2846-2853, 2013.

[17] H. J. Scherer, "The forms of growth in gliomas and their practical significance," Brain, vol. 63, no. 1, pp. 1-35, 1940.

[18] C. Gerin, J. Pallud, C. Deroulers et al., "Quantitative characterization of the imaging limits of diffuse low-grade oligodendrogliomas," Neuro-Oncology, vol. 15, no. 10, pp. 1379-1388, 2013.

[19] S. Wang and J. Zhou, "Diffusion tensor magnetic resonance imaging of rat glioma models: a correlation study of MR imaging and histology," Journal of Computer Assisted Tomography, vol. 36, no. 6, pp. 739-744, 2012.

[20] S. J. Price, R. Jena, N. G. Burnet et al., "Improved delineation of glioma margins and regions of infiltration with the use of diffusion tensor imaging: an image-guided biopsy study," American Journal of Neuroradiology, vol. 27, no. 9, pp. 19691974, 2006.

[21] H. D. Moulding, D. P. Friedman, M. Curtis et al., "Revisiting anaplastic astrocytomas I: an expansive growth pattern is associated with a better prognosis," Journal of Magnetic Resonance Imaging, vol. 28, no. 6, pp. 1311-1321, 2008.

[22] D. Le Bihan, J.-F. Mangin, C. Poupon et al., "Diffusion tensor imaging: concepts and applications," Journal of Magnetic Resonance Imaging, vol. 13, no. 4, pp. 534-546, 2001.

[23] P. Douek, R. Turner, J. Pekar, N. Patronas, and D. Le Bihan, "MR color mapping of myelin fiber orientation," Journal of Computer Assisted Tomography, vol. 15, no. 6, pp. 923-929, 1991.

[24] K. Kallenberg, T. Goldmann, J. Menke et al., "Glioma infiltration of the corpus callosum: early signs detected by DTI," Journal of Neuro-Oncology, vol. 112, no. 2, pp. 217-222, 2013.

[25] C. Pierpaoli, P. Jezzard, P. J. Basser, A. Barnett, and G. Di Chiro, "Diffusion tensor MR imaging of the human brain," Radiology, vol. 201, no. 3, pp. 637-648, 1996.

[26] T. Beppu, T. Inoue, Y. Shibata et al., "Fractional anisotropy value by diffusion tensor magnetic resonance imaging as a predictor of cell density and proliferation activity of glioblastomas," Surgical Neurology, vol. 63, no. 1, pp. 56-61, 2005.

[27] T. Inoue, K. Ogasawara, T. Beppu, A. Ogawa, and H. Kabasawa, "Diffusion tensor imaging for preoperative evaluation of tumor grade in gliomas," Clinical Neurology and Neurosurgery, vol. 107, no. 3, pp. 174-180, 2005.

[28] H. Y. Lee, D. G. Na, I.-C. Song et al., "Diffusion-tensor imaging for glioma grading at 3-T magnetic resonance imaging: analysis of fractional anisotropy and mean diffusivity," Journal of Computer Assisted Tomography, vol. 32, no. 2, pp. 298-303, 2008.
[29] I.-F. Talos, K. H. Zou, R. Kikinis, and F. A. Jolesz, "Volumetric assessment of tumor infiltration of adjacent white matter based on anatomic MRI and diffusion tensor tractography," Academic Radiology, vol. 14, no. 4, pp. 431-436, 2007.

[30] A. Stadlbauer, C. Nimsky, S. Gruber et al., "Changes in fiber integrity, diffusivity, and metabolism of the pyramidal tract adjacent to gliomas: a quantitative diffusion tensor fiber tracking and MR spectroscopic imaging study," American Journal of Neuroradiology, vol. 28, no. 3, pp. 462-469, 2007.

[31] G. Bertani, G. Carrabba, F. Raneri et al., "Predictive value of inferior fronto-occipital fasciculus (IFO) DTI-fiber tracking for determining the extent of resection for surgery of frontal and temporal gliomas preoperatively," Journal of Neurosurgical Sciences, vol. 56, no. 2, pp. 137-143, 2012.

[32] A. S. Field, A. L. Alexander, Y.-C. Wu, K. M. Hasan, B. Witwer, and B. Badie, "Diffusion tensor eigenvector directional color imaging patterns in the evaluation of cerebral white matter tracts altered by tumor," Journal of Magnetic Resonance Imaging, vol. 20, no. 4, pp. 555-562, 2004.

[33] F.-P. Zhu, J.-S. Wu, Y.-Y. Song et al., "Clinical application of motor pathway mapping using diffusion tensor imaging tractography and intraoperative direct subcortical stimulation in cerebral glioma surgery: a prospective cohort study," Neurosurgery, vol. 71, no. 6, pp. 1170-1183, 2012.

[34] S. Pujol, W. Wells, C. Pierpaoli et al., "The DTI challenge: toward standardized evaluation of diffusion tensor imaging tractography for neurosurgery," Journal of Neuroimaging, vol. 25, no. 6, pp. 875-882, 2015.

[35] S. Wakana, A. Caprihan, M. M. Panzenboeck et al., "Reproducibility of quantitative tractography methods applied to cerebral white matter," NeuroImage, vol. 36, no. 3, pp. 630-644, 2007.

[36] A. F. Santillo, J. Mårtensson, O. Lindberg et al., "Diffusion tensor tractography versus volumetric imaging in the diagnosis of behavioral variant frontotemporal dementia," PLOS ONE, vol. 8, no. 7, Article ID e66932, 2013.

[37] J. Mårtensson, M. Nilsson, F. Ståhlberg et al., "Spatial analysis of diffusion tensor tractography statistics along the inferior fronto-occipital fasciculus with application in progressive supranuclear palsy," Magnetic Resonance Materials in Physics, Biology and Medicine, vol. 26, no. 6, pp. 527-537, 2013.

[38] G. Gerig, S. Gouttard, and I. Corouge, "Analysis of brain white matter via fiber tract modeling," in Proceedings of the 26th Annual International Conference of the IEEE Engineering in Medicine and Biology Society (IEMBS '04), pp. 4421-4424, San Francisco, Calif, USA, September 2004.

[39] S. G. Berntsson, A. Falk, I. Savitcheva et al., "Perfusion and diffusion MRI combined with ${ }^{11} \mathrm{C}$-methionine PET in the preoperative evaluation of suspected adult low-grade gliomas," Journal of Neuro-Oncology, vol. 114, no. 2, pp. 241-249, 2013.

[40] A. Falk, M. Fahlström, E. Rostrup et al., "Discrimination between glioma grades II and III in suspected low-grade gliomas using dynamic contrast-enhanced and dynamic susceptibility contrast perfusion MR imaging: a histogram analysis approach," Neuroradiology, vol. 56, no. 12, pp. 1031-1038, 2014.

[41] S. Klein, M. Staring, K. Murphy, M. A. Viergever, and J. P. Pluim, "Elastix: a toolbox for intensity-based medical image registration," IEEE Transactions on Medical Imaging, vol. 29, no. 1, pp. 196-205, 2010. 
[42] R. Dambe, S. Hähnel, and S. Heiland, "Measuring anisotropic brain diffusion in three and six directions: influence of the offdiagonal tensor elements," The Neuroradiology Journal, vol. 20, no. 1, pp. 18-24, 2007.

[43] M. Thiebaut de Schotten, D. H. ffytche, A. Bizzi et al., "Atlasing location, asymmetry and inter-subject variability of white matter tracts in the human brain with MR diffusion tractography," NeuroImage, vol. 54, no. 1, pp. 49-59, 2011.

[44] M. Catani and M. Thiebaut de Schotten, "A diffusion tensor imaging tractography atlas for virtual in vivo dissections," Cortex, vol. 44, no. 8, pp. 1105-1132, 2008.

[45] M. Catani, D. K. Jones, and D. H. Ffytche, "Perisylvian language networks of the human brain," Annals of Neurology, vol. 57, no. 1, pp. 8-16, 2005.

[46] D. K. Jones, K. F. Christiansen, R. J. Chapman, and J. P. Aggleton, "Distinct subdivisions of the cingulum bundle revealed by diffusion MRI fibre tracking: implications for neuropsychological investigations," Neuropsychologia, vol. 51, no. 1, pp. 67-78, 2013.

[47] X. Guan, S. Lai, J. Lackey et al., "Revisiting anaplastic astrocytomas II: further characterization of an expansive growth pattern with visually enhanced diffusion tensor imaging," Journal of Magnetic Resonance Imaging, vol. 28, no. 6, pp. 1322-1336, 2008.

[48] A. Stadlbauer, C. Nimsky, R. Buslei et al., "Diffusion tensor imaging and optimized fiber tracking in glioma patients: histopathologic evaluation of tumor-invaded white matter structures," NeuroImage, vol. 34, no. 3, pp. 949-956, 2007.

[49] R. Seizeur, N. Wiest-Daessle, S. Prima, C. Maumet, J.-C. Ferre, and X. Morandi, "Corticospinal tractography with morphological, functional and diffusion tensor MRI: a comparative study of four deterministic algorithms used in clinical routine," Surgical and Radiologic Anatomy, vol. 34, no. 8, pp. 709-719, 2012.

[50] M. L. Mandelli, M. S. Berger, M. Bucci, J. I. Berman, B. Amirbekian, and R. G. Henry, "Quantifying accuracy and precision of diffusion MR tractography of the corticospinal tract in brain tumors: clinical article," Journal of Neurosurgery, vol. 121, no. 2, pp. 349-358, 2014.

[51] F. Szczepankiewicz, S. Lasič, D. van Westen et al., "Quantification of microscopic diffusion anisotropy disentangles effects of orientation dispersion from microstructure: applications in healthy volunteers and in brain tumors," NeuroImage, vol. 104, pp. 241-252, 2015. 


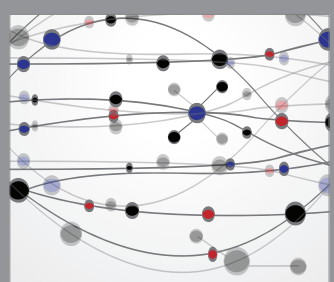

The Scientific World Journal
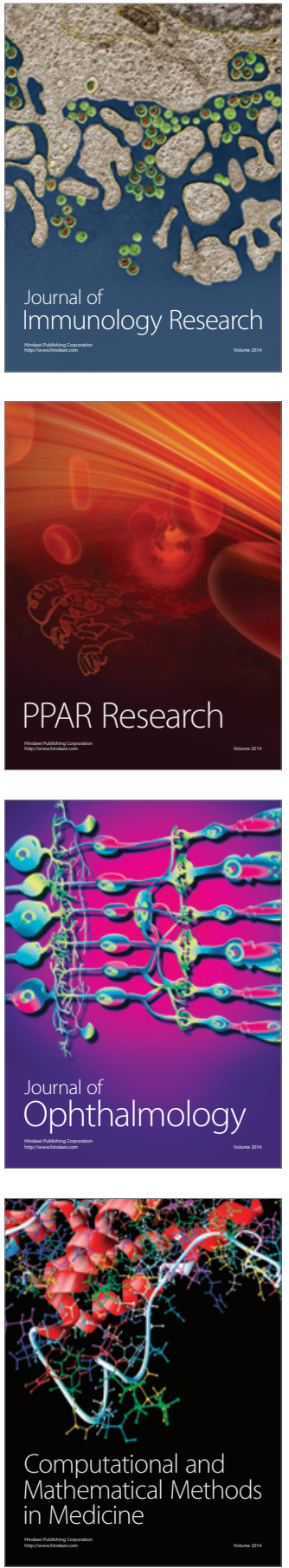

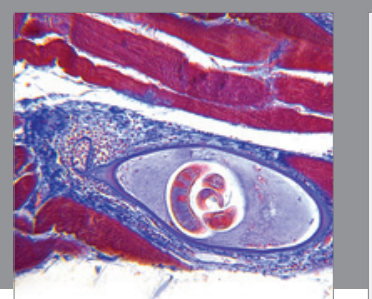

Gastroenterology Research and Practice

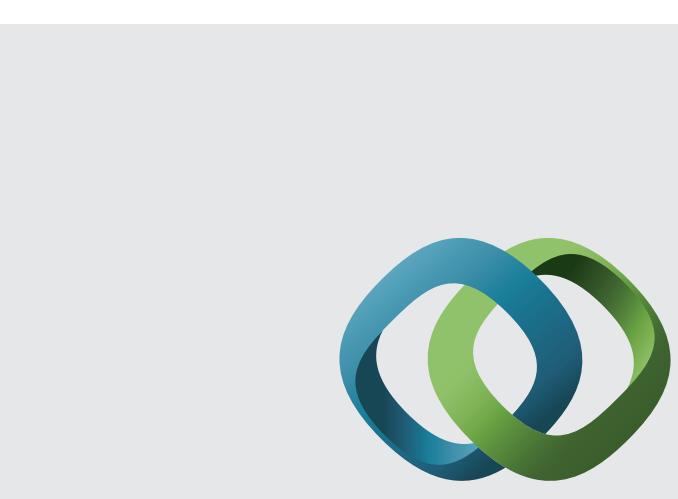

\section{Hindawi}

Submit your manuscripts at

http://www.hindawi.com
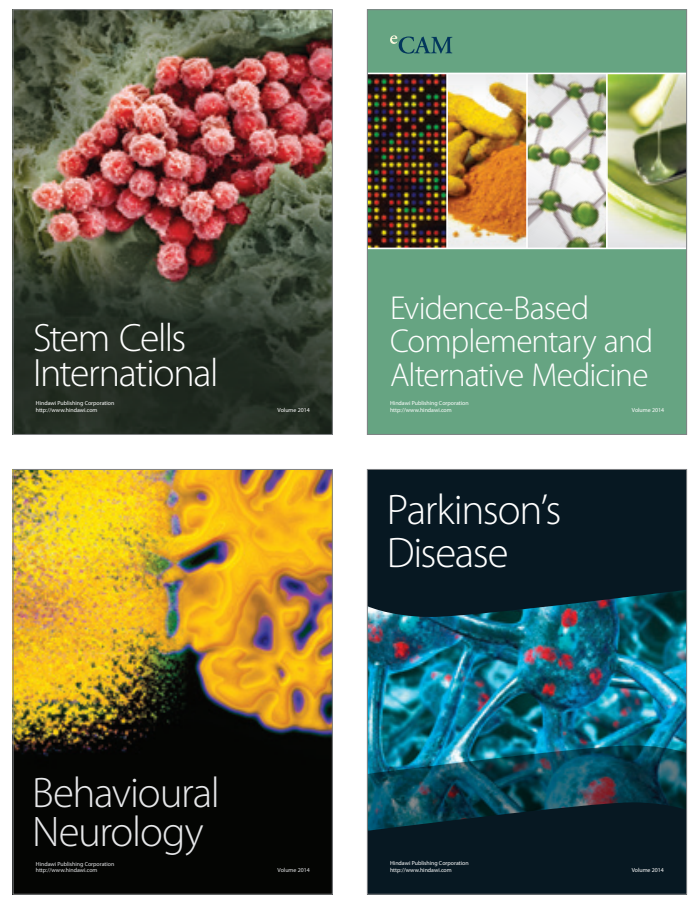
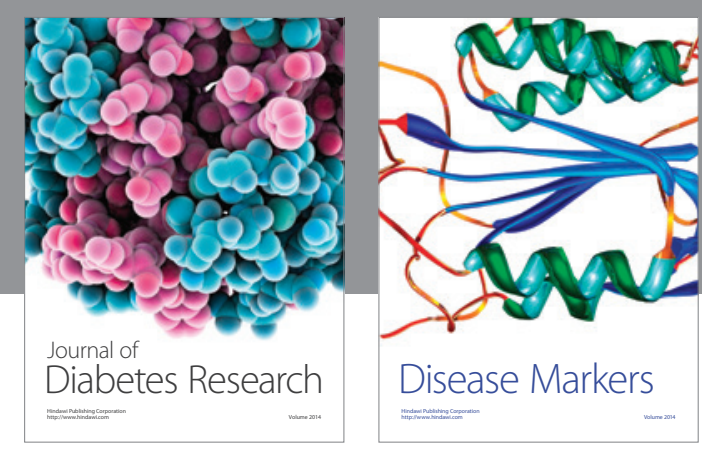

Disease Markers
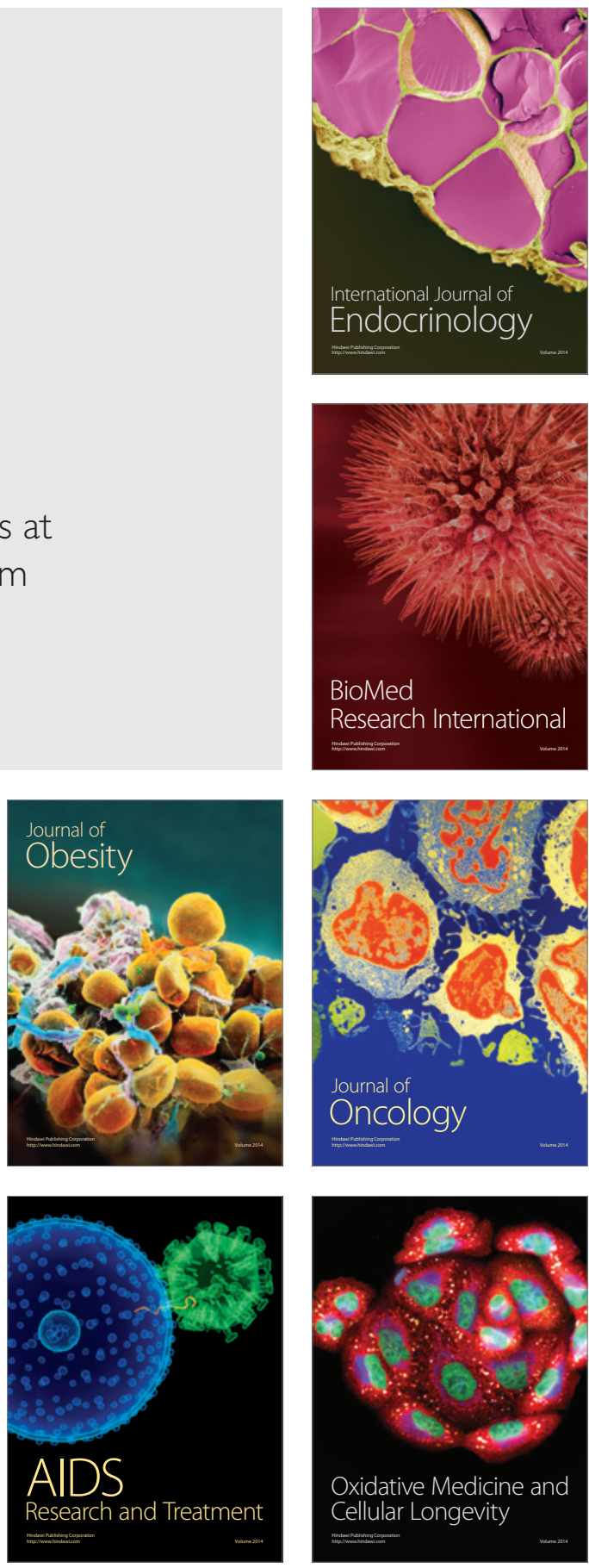